doi:10.1017/S1041610209991165

\section{Elderly suicides by drug poisoning in England and Wales: time trends within two elderly age-bands}

It is believed that a better understanding of the methods used by older people for suicide may lead to the development of targeted preventative strategies, which are expected to meet the challenge of sustaining this observed decline in suicide rates among older people over time in England and Wales (Lindesay, 1991; Dennis and Lindesay, 1995).

A number of previous studies have found that drug poisoning is the most common method of suicide used overall by the elderly (Lindesay, 1986; Cattell and Jolley, 1995; Tadros and Salib, 2000), and more prevalent in elderly women than elderly men (Lindesay, 1986; Cattell and Jolley, 1995; Shah and De, 1998). Although earlier studies have found that there has been a trend towards a decline in suicide by drug poisoning in older adults, this was primarily as a result of the reduction in deaths from barbiturate poisoning (Nowers and Irish, 1988; Lindesay, 1991). Now that barbiturate prescribing has been largely restricted for a number of years, there is a need for an update on the trends in drugs used by older people to commit suicide by poisoning, in both sexes, in different elderly age bands.

Data for England and Wales on suicides by drug poisoning (ICD-10 categories X60-X64) and open verdicts (ICD-10 categories Y10-Y14), for the seven-year period 2001-2007, was ascertained from the U.K. Office of National Statistics (http://www.statistics.gov.uk/statbase/Product.asp? vlnk=618). Data on suicides and open verdicts by drug poisoning were available for 21 five-year agebands for both sexes. These data were collapsed into those aged 65-74 years and those aged $75+$ years.

The numbers of suicides by poisoning for ICD-10 categories $\mathrm{X} 60 \& \mathrm{Y} 10$ to $\mathrm{X} 64 \& \mathrm{Y} 14$ were calculated for those aged 65-74 years and those aged $75+$ years, in both sexes, for each year across the study period. Time-trend analysis was performed in order to establish the rate of suicide over the seven years for total suicides by drug poisoning and for each individual methods of drug poisoning, for older men and women in the age categories $65-74$ and 75 and over. This was examined with Spearman's correlation coefficient $(\rho)$.

The findings are presented in Table 1. During the period 2001-2007, there was a significant reduction in total rates for suicide by drug poisoning for men in the age band 65-74 years; however, there were no significant changes in total suicide rates by drug poisoning for men in the $75+$ age band. Likewise, between 2001 and 2007 there was a significant reduction in total rates for suicide by drug poisoning for women in the 65-74 age band; however, there were no significant changes for women in the $75+$ age band during this period.

For the individual methods of suicide by drug poisoning, there was a significant reduction in the rates of suicide by "other and unspecified drug, medicaments and biological substances" for men aged $65-74$ in the study period. In addition, there was a significant reduction in the rates of suicide by "non-opiod analgesics, antipyretics and antiheumatics" in women in both elderly age bands.

This study found that although suicide rates by drug poisoning were declining in both men and women in the 65-74 age group, there was no change in rates in the $75+$ age band for either sex, between 2001 and 2007. There could be a number of

Table 1. The relationship between males ( $65-74$ and $75+$ years) and females (65-74 and 75+ years) and individual rates of suicide by drug poisoning, 2001-2007

\begin{tabular}{|c|c|c|c|c|}
\hline ICD-10 CODE & MALES $65-74$ & MALES $75 \pm$ & FEMALES $65-74$ & FEMALES $75 \pm$ \\
\hline X60 \& Y 10 & NS & NS & $\rho=-0.85, \mathrm{p}<0.05$ & $\rho=-0.78, \mathrm{p}<0.05$ \\
\hline $\mathrm{X} 61 \& \mathrm{Y} 11$ & NS & NS & NS & NS \\
\hline $\mathrm{X} 62 \& \mathrm{Y} 12$ & NS & NS & NS & NS \\
\hline $\mathrm{X} 63$ \& Y 13 & NS & NS & NS & NS \\
\hline $\mathrm{X} 64 \& \mathrm{Y} 14$ & $\rho=-0.96, \mathrm{p}<0.01$ & NS & NS & NS \\
\hline Total & $\rho=-1, \mathrm{p}<0.01$ & NS & $\rho=-0.86, \mathrm{p}<0.05$ & NS \\
\hline
\end{tabular}

NS = not significant

$\mathrm{X} 60$ \& Y10 = poisoning by and exposure to non-opiod analgesics, antipyretics and antirheumatics; X61\& Y $11=$ poisoning by and exposure to anti-epileptic, sedative-hypnotic, antiparkinsonism and psychotropic drugs; X62 \& Y12 = poisoning by and exposure to narcotics and psychodysleptics [hallucinogens]; X63 \& Y13= poisoning by and exposure to other drugs acting on the autonomic nervous system; X64 \& Y14 = poisoning by and exposure to other and unspecified drugs, medicaments and biological substances. 
explanations for this. It is possible that the $65-74$ age group, due to better physical health and mobility, were more able to turn to alternative methods than the $75+$ group; the older group would be more likely to have been in physical pain and hence have access to more medication; and, despite a number of initiatives, the health of older adults is still largely neglected, and this may be more apparent as they reach the age of $75+$. In addition, their prescriptions may not be being monitored correctly, giving them more opportunity to die by overdose.

The reduction in rates for suicide by "non-opiod analgesics, antipyretics and antiheumatics" in elderly women in both age bands are contrary to those previously observed (Lindesay, 1986; Nowers and Irish, 1988; Shah and De, 1998). A number of studies have found that the decline in suicides by barbiturates was partially offset by an increase in the number of suicides by non-opiate analgesics (Lindesay, 1986; Nowers and Irish, 1988; Dennis, 1995; Shah and De, 1998), especially among older women (Nowers and Irish, 1988; Shah and De, 1998). This decline among elderly women, and the lack of an increase among elderly men, is therefore encouraging.

The availability of method is an important factor in suicide (Kelly and Bunting, 1998), and for elderly people it is relatively easy to stockpile medication, requiring little physical effort. The evidence for the fall in suicides by barbiturates indicates that removal of means is an effective preventative strategy in the elderly, and that more careful prescribing practices could lead to a lower suicide rate in this age group. In light of the results of this study, it must be recognized that different methods of suicide by drug poisoning show declines in different elderly age and sex bands, and hence there is a need to aim particular preventative strategies at these different groups.

doi:10.1017/\$1041610209991451

\section{A replication of the curvilinear relationship between population growth and elderly suicide rates in a cross-national study}

A curvilinear (U-shaped) relationship between population growth rates and elderly suicide rates fitting the quadratic equation $y=a+b x+$ $c x^{2}$ (where $y$ is the elderly suicide rate, $x$ is the population growth rate and $a, b$ and $c$ are constants) has been reported (Shah, 2009a). A theoretical model with three sequential stages incorporating

\section{Acknowledgments}

We are grateful to the University of Central Lancashire for funding LB as a student intern to conduct this research.

\section{References}

Cattell, H. R. and Jolley, D. (1995). One hundred cases of suicide in elderly people. British fournal of Psychiatry, 166, 451-457.

Dennis, M. and Lindesay, J. (1995). Suicide in the elderly: the United Kingdom perspective. International Psychogeriatrics, 7, 263-274.

Kelly, S. and Bunting, J. (1998). Trends in suicide in England and Wales, 1982-1996. Population Trends, 92, $29-41$.

Lindesay, J. (1986). Trends in self-poisoning in the elderly 1974-1983. International fournal of Geriatric Psychiatry, 1, 37-43.

Lindesay, J. (1991). Suicide in the elderly. International Fournal of Geriatric Psychiatry, 6, 355-361.

Nowers, M. and Irish, M. (1988). Trends in the reported rates of suicide by self-poisoning in the elderly. Fournal of the Royal College of General Practitioners, 38, 67-69.

Shah, A. K. (2007). Elderly suicide rates in the United Kingdom: trends from 1979 to 2002. Medicine, Science and the Law, 47, 56-60.

Shah, A. K. and De, T. (1998). Suicide in the elderly. International fournal of Psychiatry in Clinical Practice, 2, 3-17.

Tadros, G. and Salib, E. (2000). Age and methods of fatal self-harm (FSH). Is there a link? International fournal of Geriatric Psychiatry, 15, 848-852.

\footnotetext{
LAURA BUCKLEY ${ }^{1}$ AND AJIT SHAH ${ }^{1,2}$

${ }^{1}$ International School for Communities, Rights and Inclusion, University of Central Lancashire, Preston, U.K.

${ }^{2}$ West London Mental Health NHS Trust, London, U.K. Email: laurajanebuckley@yahoo.com
}

population growth, elderly population size, the proportion of elderly in the general population, life expectancy and birth rates has been proposed to explain the findings (Shah, 2009a).

An identical curvilinear relationship was also observed between "predicted" future population growth rates and elderly suicides (Shah, 2009b). As "predicted" future population growth, which has not yet occurred, cannot directly explain an increase in suicide rates, the accuracy of the curvilinear relationship between population growth and elderly suicide rates has been questioned (Shah, 2009b). The "predicted" future population growth rate may 